\title{
'Calling our spirits home': Indigenous Cultural Festivals and the Making of a Good Life
}

\section{Lisa Slater}

Speaking about the problems affecting Wik youth of Aurukun, Cape York, a local community health worker, Derek Walpo, lamented that 'their spirits have wandered too far. We need to call them back.' The poignant reflection was made at a debriefing session following a social and wellbeing festival in Aurukun. ${ }^{\top}$ The five-day event culminated in a Mary G concert, in which almost all the township gathered to laugh and cheer the indomitable Broome 'lady'. It was not just Mary G's ribald humour that vitalised and galvanised the crowd, but also her performance that playfully reflected back and validated some of the locals' experiences and values, such as humour in the face of hardship. Derek was emphasising the importance of community celebrations and cultural ceremony as vehicles for improving the wellbeing of Aboriginal youth and community. Without denying or eclipsing the specificity of his remark, I would suggest that he was referring to an existential problem: the young people are overwhelmed by the dominant culture and fracturing local life and have lost a purpose of existence. His words underscore the ephemeral qualities that are vital to a good life. More, he evokes Indigenous life worlds that the settler-colonial state finds difficult to countenance.

What makes a good life? What allows people to flourish? Many words have been spent on calling the 'crisis' in Indigenous Australia. In 2008, the Minister for Indigenous Affairs, Jenny Macklin, spoke of Aurukun in a speech titled 'Out of the Chaos' as: 
as tragic a place as you'll find ... It is a depressing broken community with the depressingly familiar symptoms of widespread breakdown in social norms - child abuse, alcoholism, suicide, welfare dependency, third world health and education. And above all, an abiding and pervading loss of purpose. ${ }^{2}$

She went on to say that Aurukun was 'typical of the dysfunction and breakdown of social norms that exist in many, many Indigenous communities'. ${ }^{3}$ Her concerns are widely shared; the solutions less so, as we witness with the continuing debate about the Northern Territory Intervention. Although I too share the distress, as I have written elsewhere, the language of brokenness and dysfunction troubles me. ${ }^{4}$ Such rhetoric, and the often-attendant graphic images, overwhelms most with thoughts of helplessness and hopelessness, and we want for governments to rescue us from the pain of bearing witness to what is essentially the workings of colonialism. What the rhetoric of crisis and dysfunction also does is foreclose upon alternative interpretations of what nourishes life.

As we are well aware, recent governments have acted on the growing number of reports and voices detailing the social distress in too many Indigenous people's lives. The current 'crisis' in Indigenous Australia is largely responded to by government agencies by their reinforcement of mainstream values and experiences - as can be seen in the 'Close the Gap' campaign and the Intervention. 5 The prevalent government approaches to improving the health and wellbeing of Indigenous Australians, as Jon Altman writes, are aimed at socioeconomic equality, and often ignore colonial history and the diversity of Indigenous circumstances and sociocultural distinctiveness. In Altman's words, Indigenous affairs 'looks for mainstream solutions to deeply entrenched nonmainstream problems'. ${ }^{6}$ In so doing, there is an assumption that what constitutes Indigenous wellbeing, or what makes for a good life, is roundly shared with mainstream Australia.

Despite reports as influential as 1997's Bringing Them Home recommending Indigenous cultural heritage and identity as important to wellbeing, ${ }^{7}$ there has been a failure by governments and mainstream agencies to engage with 
Indigenous culture as a material expression of a vital life force, thus integral to wellbeing, or, put more poetically, calling people's spirits home. In his assessment of the Close the Gap campaign Altman asks how, in all this, 'are Indigenous people, in all their diversity, being enabled "to do and to be"?'8 In this essay I examine contemporary performances of Indigenous 'doing and being' through the lens of two cultural festivals: Laura Dance and Cultural Festival (Cape York) and the Dreaming Festival (southeast Queensland). Indigenous organisations, communities or individuals run a diversity of cultural festivals. Yet when I ask people to explain why festivals are worth having I hear very similar responses: to celebrate, share and, most importantly, maintain culture. To a lesser extent they are vehicles for economic development. The festivals are fundamentally about sustaining Indigenous worlds: the very life worlds that are not being valued in the race for statistical equality.

\section{Being well}

How health and wellbeing is understood and defined has far-reaching effects on policy and its implementation. Indeed, dominant definitions could be bad for some people's health. Wellbeing, Ian Anderson writes, 'implies the act to be', which has a particular emphasis on the social aspects of being. 9 Thus social, cultural and historical differences will produce differences in what it is to be a healthy, capable person and what constitutes a good life. We have all benefited from developments in medical science. However, it is based upon an ideology of the Western concept of the self: a self-contained, independent individual separate from family, community and country. ${ }^{10}$ In prioritising individual health over social health, the individual is abstracted from the environment in which they live and how they make meaning of and in their life. Furthermore, it is assumed that there is a shared understanding of, desire for, and primacy of, a specific 'healthy' body, which takes precedence over cultural, spiritual or moral interests. ${ }^{11}$ This is only one way of conceptualising health and wellbeing. Daniela Heil believes there is a need to understand the person not as a monadic individual but as always in the process of being constituted in social relations, and thus 
relationships between people and their ongoing reconstitutions and affirmations is what makes life worth living. ${ }^{12}$

Like Heil, I do not want to pit essentialisms against each other - the dehumanising biomedical world against a benign Aboriginal cultural world. Rather, following Lenore Manderson, I want to suggest that wellbeing is not the state of individual bodies but of bodies in society. ${ }^{13}$ This is not to deny personal history or circumstances that affect our wellbeing, but rather, as my colleagues write, 'to recognise that our social and communal life-world is not simply the contextual background to our wellbeing but fundamentally constitutive of it'. ${ }^{14}$ To improve Indigenous health and wellbeing requires not only a concern for biomedical health but also an exploration of what Indigenous people believe constitutes a 'good life' and the immediate and broader social, cultural and political circumstances that enable and disable a state of wellbeing. What is too often omitted, but should be central to government aims and policies, is a respect for how Indigenous people, in all their differences, are shaping their own lives in accordance with their sociocultural values and experiences of what makes life meaningful. ${ }^{15}$ Wellbeing, health or healthy body, is not a neutral concept; as much as it is a highly ethical project it is also political.

\section{Governing difference}

Notably, government responses such as the Intervention in the Northern Territory are concerned with the Indigenous social body; however, indigeneity is too readily presented as dysfunctional and in need of rescuing and recuperating into the 'healthy' civic body. ${ }^{16}$ In Australian public discourse the Indigenous population is almost always characterised as disadvantaged or deficient compared to the non-Indigenous. Indigeneity is structured through comparison with nonIndigenous population data across a range of socioeconomic indicators like health status, education and employment levels, income and housing. These comparisons have awakened mainstream Australia to vast inequalities, but the discursive frame continues to disable an engagement with Indigenous lived experience, values and aspirations. Imaginatively relocating Indigenous people from the margins to the centre 
has material effects on lives that are often overlooked in the race for equality. Recognition of gross social inequalities can prompt urgent action by the state and community. It also implicitly, if not deceptively, foregrounds the kind of social ideals state and community organisations should aim for: social norms based on non-Indigenous, national ideals of experience and wellbeing. In the pressing moral and political objective of achieving statistical equality, as John Taylor observes, Indigenous people's own life projects can be obscured. ${ }^{17}$ If the critical goods of health and wellbeing, as is widely accepted, are leading a life with purpose, having quality connections with others, possessing self-regard and experiencing feelings of efficacy and control than the inability of the state to accommodate and value multiple interpretations of a 'good life' severely impedes goals for positive change. ${ }^{18}$

The forces that nourish many Indigenous lives, such as country, kinship sociality, spirits and law-what broadly could be referred to as culture - are seen as an encumbrance to, or outside, the healthy national sociopolitical body and thus incommensurate with the goals of government policy. The vision of Australian modernity, Kerry Arabena writes, has a resolutely white construct of the 'modern citizen'. The processes of Indigenous affairs are making Indigenous people fit for the modern nation, she argues, by resisting and minimising the recognition of cultural and historical differences. ${ }^{19}$ I would add that this is because the 'inheritors' of modernity, and thus political sovereignty, enact a particular mode of citizenship that cannot capture the specificity of Indigenous subjectivities. Yet it is this mode that is invoked as the benchmark for statistical equality and practical reconciliation. The modern is secular, disembodied and separate from the nonhuman world. ${ }^{20}$ The social/public is the space for a particular performance of subject-citizen and by embodying this position one is 'taking their rightful place in the social realm'. ${ }^{21}$ To be otherwise is a demonstration of not yet being modern. There are too few public spaces that foster alternative performances of healthy citizens. Indigenous spirituality and cultural heritage is tolerated in mainstream politics as a lingering anachronism or as an ancient and worthy culture, but it is rarely understood as fundamental to Indigenous wellbeing. 


\section{Kicking up dust}

Festivals and community celebrations have longed been vehicles for important communal functions - a part of the process of creating community and nourishing belonging - and in so doing defining and making connections between people and place: including and excluding. ${ }^{22}$ Throughout the history of the Australian nation, Indigenous people have participated in festivals commemorating nationhood, and have staged counter festivals to protest against colonisation, to celebrate survival and to share and keep their culture strong. ${ }^{23}$ Festivals are a means of entering into dialogue with mainstream Australia and testimony to ongoing political struggles, and for both Indigenous performers and their audience these settings provide an important context for the contemporary negotiation and transmission of Indigenous people's identities. ${ }^{24}$

Cultural festivals, as Rosita Henry asserts, allow Indigenous people to make themselves present to the world and to challenge a history that had rendered them absent. ${ }^{25}$ To be 'rendered absent' from history is to be made marginal to the civic body, which reinforces the values of the settlercolonial culture. When this happens, the sociocultural differences that are life sustaining and generative do not inform the very government policies created to improve Indigenous lives. Indigenous cultures have long been denigrated, misunderstood, discounted and appropriated; they have been made meaningful or meaningless through a colonial lens, but rarely recognised as material expressions of worldviews and sociality that anchor and tend life. I am in no way suggesting that festivals are the only or only remaining space where 'culture' is performed, of course this is in no way true-culture is lived in the everyday. However, what is well documented, and most especially etched into the lives of Indigenous people, is the assimilaitive pressures upon peoples who are embedded within a dominant culture. A vital component of sustaining and supporting wellbeing is the creation of public spaces in which Indigenous culture can asssert itself over and against the social construction of reality by the mainstream. ${ }^{26}$

The Dreaming Festival strives to present rich and distinct Indigenous cultural histories, and affirm Indigenous people as historical agents. The festival, held in June near Woodford 
in southeast Queensland, began in 2005. It showcases local, national and international Indigenous artists in a contemporary celebration of culture and Indigenous excellence. Held over three days and four nights, the program features film and literature components, performing arts, new media and digital technologies, comedy, ceremony, exhibitions, performance artists, physical theatre, visual arts, craft workshops, music program, street performers, musicals and a youth program and forums. While the impact of the Dreaming on the Murri host community of Jinibara land is extremely important to understand, the emphasis of this festival is not specifically local, and involves participation on a much larger scale.

The festival does not privilege a particular representation of Indigeneity; rather, it gathers a diversity of performers and forum participants from vastly different places. As I have written elsewhere, the range of performances and divergent identities presented at the Dreaming defies anyone's ability to define and categorise Indigenous identity. The Dreaming offers far more than an avenue for the expression of Indigenous culture: cultural performance provides a space for representation and identity formation, and also a political engagement and critique of the dominant culture. The display of cultural plurality, yet political solidarity, is not only a refusal of the neoliberal colonial state's agenda of homogeneity, but also a demonstration that the making of a 'good life' might require the valuing of difference as much as equality.

Among the dust, four-wheel drives, tents, towering eucalypts and the whirl of kids is the Laura Dance and Cultural Festival performance grounds. The Laura festival began in the early 1980 os and is held biennially, fifteen kilometres from the township of Laura, Cape York, Queensland, on Kuku Yalanji land. The three-day program is a celebration of the region's Indigenous cultures; it primarily features dance groups from across Cape York and into the Torres Strait, but there are also long-standing participants from Mornington Island, Yarrabah and Palm Island. The 2009 festival - the eighteenth - saw troupes from as far as Inala, Brisbane. Every year nonIndigenous people from across Australia, and international guests, are welcomed onto country to experience the strength of Cape York Indigenous cultural heritage. 
When Jeremy Gaia became the festival director it was made very clear to him by Indigenous communities of Cape York that they wanted Laura to return to a grassroots festival, with the express purpose of keeping culture strong through dance, story and art and to demonstrate sovereignty. ${ }^{27}$ In an era of Indigenous affairs in which 'self-determination' has all but become a dirty word, where government interventions are imposed upon communities and Indigenous culture is routinely derided as a hindrance to socioeconomic wellbeing (yet there is a stated - and no doubt genuine-commitment to improving Indigenous lives), the communities' dedication to the Laura festival should be pause for reflection. It is no small feat to get a small plane of people from the outer Torres Strait Islands to Laura, or a busload from Injinoo over the dusty track of the Peninsula Development Road which cuts through the Cape-or from Inala for that matter. Nor is it to feed, water and shelter everyone - all such supplies needing to be flown or driven in by the visiting groups. People do so because for them 'culture' is not an impediment to a 'good life' but its very substance.

To borrow the words of Alfred Dockery, 'Australians should care, first and foremost, about the wellbeing of those Indigenous people in urgent need. This surely involves maintaining the things that they value, not destroying them'. ${ }^{28}$ The peoples of Cape York's passion for and commitment to the Laura Dance Festival as a vital initiative in maintaining culture and strengthening identity was made clear in a two-day workshop that was held in Cairns in May 2008 by the Aboriginal and Torres Strait Islander Arts Board (ASTIAB). ${ }^{29}$ Participants undertook an exercise to arrive at the festival purpose or mission statement. Despite the range of people and communities in the room, it did not take long for consensus to emerge: the festival's mission was to maintain and develop strong culture for the Cape and surrounding communities. The country men and women were unambiguous that Laura Festival is a significant event for bringing Indigenous people together from across the Cape, which is necessary for maintaining cultural integrity and passing on tradition to young people. Old men rose to their feet to stress their support for the festival and its role in gathering the cultures from across 
the Cape to strengthen and affirm their sovereignty, and as a means for sustaining their life worlds.

In mainstream health and wellbeing research, it is widely acknowledged that a strong sense of identity is a prerequisite for mental health, ${ }^{30}$ yet there are few opportunities to assert the importance of cultural heritage and identity as a vital component in Indigenous wellbeing. Furthermore, cultural identity depends not only on access to culture and heritage but also on an opportunity for cultural expression and endorsement within society's institutions. ${ }^{31}$ For Indigenous Australians there are few avenues to do this and people's experiences are seldom respected. Laura Festival provides a space in which Indigenous values take precedence. The country men and women's faith in their sociocultural processes to generate wellbeing parallels the beliefs of many health professionals who argue that innovative public health policies must deal with the root causes of social exclusion while at the same time respecting the unique ways that people draw meaning from their life experiences, take strength from belief systems and value particular social institutions..$^{32}$

The forces that nourish life can be evoked but not necessarily measured. At the Dreaming Festival I used photonarrative methods to illicit deeper discussions about young Indigenous people's sense of the festival. I asked a number of people to take digital photographs of their 'Dreaming experience', and then, as we reviewed the images - much like looking through holiday snaps - the participants chose particular images to talk to and help articulate their experiences, thoughts and feelings. All interviewees enjoyed the festival: in a general sense they had fun and it was an opportunity to mix it up with Indigenous people, young and old, from across the country and internationally. But much more profoundly it inspired hope not only because it is a showcase of Indigenous excellence, but also because it is a place of exchange, where participants could feel the spiritual strength of people and culture. Carl said that he felt the pride of the kids, and they were not subject to the shame they feel in the mainstream, which allowed them to reconnect with their 'internal compass'.

Thomas spoke eloquently of cultural gatherings, such as the Dreaming Festival, providing a stable platform for the next 
generation. He emphasised the festival's role in maintaining the structures of life. We need, he told me, to attend to the foundations of life and he saw the Dreaming Festival as contributing to creating places where people can 'take off from': a generative force that enables young Indigenous people to participate in broader Australian life. ${ }^{33}$ Performances of cultural heritage, in all its different modes, reassure people of their permanence and the legitimacy of their worldview, ${ }^{34}$ and in so doing, nurture life. Thomas's thoughts are reminiscent of what Mick Dodson sees as Indigenous peoples' twin projects, one of which is to 'subvert the hegemony over our own representations, and allow our visions to create the world of meaning in which we relate to ourselves, to each other, and to non-Indigenous people'.35 Indigenous cultural festivals, such as Laura and the Dreaming, provide much needed social spaces for affirming Indigenous visions and aspirations in a non-subservient relation to mainstream values.

We might hope that history has taught us that no matter how 'good' the intentions, what makes life worth living cannot be imposed upon peoples by the dominant culture. If wellbeing is fundamentally about 'the act to be', then social and cultural distinctive understandings of what makes a healthy Indigenous person are of primary importance. Social and communal life-worlds are vital for everybody's daily sustenance. What is evident in contemporary Indigenous affairs, and public discourse in general, is that Indigenous people and communities are characterised as dysfunctional and deficient compared to mainstream Australia, which reinforces white, settler-colonial values and experiences of wellbeing. Indigenous health requires creating public spaces in which Indigenous reality can be asserted over mainstream culture. Performances of cultural heritage and identity are vital elements in legitimising, sharing and challenging worldviews. They enable processes of creativity and renewal. People gather to not only celebrate Indigenous cultures but also to tend dynamic living cultures; in this sense the festivals are spaces for performing, discussing and negotiating contemporary culture and identity. Festivals such as Laura and the Dreaming are sociocultural spaces in which people are affirming worlds of meaning and the conditions of a good life. 


\section{Reflection}

In April 2014, the organisations People Culture Environment (PCE) and Our Generation Media released The Elders' Report into Preventing Indigenous Self-Harm and Youth Suicide. It's a devastating read. In his report summary, the PCE Chair and Yuin Elder, Max Harrison, writes: 'It was developed in response to a massive and unprecedented increase in Indigenous youth self-harm and suicide that has occurred over the past twenty years across Australia's Top End.' ${ }^{36}$

The report is comprised of transcriptions of interviews with Elders and community leaders from affected communities, who want to speak publically about how to address this overwhelming issue. Until the last few decades, self-harm and suicide was extremely rare, now the Kimberley region has the highest Indigenous suicide rate in the world. The Elders were asked two questions: What is the cause? What is the solution? Despite the diversity and differences of views, Harrison notes that there was a 'high level of agreement between the speakers about the role culture and loss of cultural connection plays in making young people vulnerable to self-harm'. The Elders are asserting the important role of culture for creating a good life.

My essay reproduced here was the culmination of a three-year research project examining the impact of Indigenous cultural festivals on socio-cultural wellbeing. We did not propose to address issues as devastating as youth suicide. However, reading the Elders' report, I heard the echo of Derek Walpo's poignant reflection: 'Their spirits have wandered too far. We need to call them back.' He too was gravely concerned about young people in Aurukun, especially men. Like many people I interviewed, he supported festivals as a means to connect youth to their culture. In the contemporary era of mainstreaming Indigenous programs and services, this thing called 'culture' is not always a good fit with neoliberalism. Culture as spectacle, commodity or artefact is appreciated and often valorised, but I don't think this is what the Elders of Northern Australia have in mind.

During the research project, I spoke to a lot of people. Hundreds. When I asked, 'Why are festivals important?' time and time again the response was, 'To keep culture strong'. Why? To keep young people strong. Notably more Indigenous than non-Indigenous people used this phrase. Yet still this thing called 
Indigenous culture gets called into service - seemingly named as the main game in town - in significant and numerous government and non-government policy documents. Tony Abbott's government has recently streamlined Indigenous Affairs from 150 individual programs to five. One of the priority areas of the 'new Indigenous Advancement Strategy' is culture and capability: the 'programme will support Indigenous Australians to maintain their culture'. ${ }^{37}$

The government is purportedly committed to culture. So why then are Elders from Cape York to the Kimberley calling for governments and mainstream agencies to recognise the vital importance of connecting young people to culture and country?

Maybe I'm asking the wrong question. What work does maintaining culture do? What are the Elders recognising and valuing? I doubt it is the same as the government. Yet these different, if not incongruent meanings, meet or rather collide in intercultural spaces, where there might be shared goals: improving people's lives. And this is the rub. It is easy to accuse previous governments, and all manner of Australians, of neglect: at the very least indifference to Indigenous Australia. And there is plenty of evidence. However, I think that cultural studies can play a more productive role. We can approach these spaces as complex political ecologies, embrace the messiness, and take multiplicity seriously. And in so doing, take people, culture and country seriously, which is what I think the Elders' report is asking us to do.

\section{Notes}

The meeting took place in Aurukun on 3 October 2008 after the Kemp Min, Kuchek Min festival held by Queensland Forensic Health. Jenny Macklin, 'Out of the Chaos', Melbourne Institute Economic and Social Outlook Conference, Melbourne, 27 March 2008, http://www.jennymacklin. fahcsia.gov.au.

3 Ibid.

4 Lisa Slater, “'Aurukun, We're Happy, Strong People”: Aurukun Kids Projecting Life into Bad Headlines', Borderlands e-journal, vol. 7, no. 2, 2008.

5 Kerryn Pholi, 'Is 'Close the Gap' a Useful Approach to Improving the Health and Wellbeing of Indigenous Australians?', Australian Review of Public Affairs, vol. 9, no. 2, 2009, pp. 1-13; Jon Altman and Melinda Hinkson (eds), Coercive Reconciliation: Stabilise, Normalise, Exit Aboriginal Australia, Arena Publications, Melbourne, 2009.

6 Jon Altman, 'Beyond Closing the Gap: Valuing Diversity in Indigenous Australia', paper presented at the Values and Public Policy: Fairness, Diversity and Social Change conference, Centre for Public Policy, University of Melbourne, 26-27 February, 2009, p. 1. 
Human Rights and Equal Opportunity Commission, Bringing Them Home: A Report of the National Inquiry into the Separation of Aboriginal and Torres Strait Islander Children from their Families, Human Rights and Equal Opportunity Commission, Sydney, 1997.

8 Altman, p. 14.

9 Ian Anderson, 'Powers of Health - On the Politics of Self-Determining Aboriginal Health', Arena Magazine, no. 11, 1994, p. 36.

10 Heather McDonald, Kerry Arabena and Graham Henderson, 'Aboriginal and Torres Strait Islander Health and Healing', Australian Aboriginal Studies, vol. 2, 2006, p. 1.

11 Danielle Heil, 'Shifting Expectations of Treatment: From "Patient as Individual" to "Patient as Social Person", Australian Aboriginal Studies, vol. 2, 2006, p. 100.

12 Heil, p. 10o. My emphasis.

13 Lenore Manderson, 'Introduction: The Social Context of Wellbeing', in Lenore Manderson (ed.), Rethinking Wellbeing, Curtin University Publishing, Perth, 2005, p. 12.

14 Martin Mulligan, Kim Humphrey, Paul James, Christopher Scanlon, Pia Smith and Nicky Welsh, Creating Communities: Celebrations, Arts and Wellbeing Within and Across Local Communities, Globalism Institute, RMIT University, Melbourne, 2006, p. 25.

15 Folds in Vicki Grieves, Indigenous Wellbeing: A Framework for Governments' Aboriginal Cultural Heritage Activities, NSW Department of Environment and Conservation, June 2006, http://www.environment.nsw.gov.au/resources/ cultureheritage/grievesreport2006.pdf.

16 Slater, p. 12.

17 John Taylor, 'Indigenous People and Indicators of Well-being', Centre for Aboriginal Economic Policy Research Working Paper, Australian National University, Canberra, 2006, p. 8.

18 Manderson, p. 162.

19 Kerry Arabena, 'Not Fit for Modern Australian Society: Aboriginal and Torres Strait Islander People and the New Administration for Indigenous Affairs', AIATSIS Research Discussion Paper, no. 16, Canberra, 2006, p. 14.

20 Dipesh Chakrabarty, Provincializing Europe: Postcolonial Thought and Historical Difference, Princeton University Press, Princeton 2000, p. 15.

21 Ibid., p. 131.

22 See Mulligan et al.; Michelle Duffy, 'Performing Identity within a Multicultural Framework', Social and Cultural Geography, vol. 6, no. 4, 2005, p. 677-92.

23 Rosita Henry, 'Festivals', in Sylvia Kleinert and Margo Neale (eds), The Oxford Companion to Aboriginal Art and Culture, Oxford University Press, Oxford, p. 586; KALACC, New Legend, Kimberley Aboriginal Law and Cultural Centre, Fitzroy Crossing, 2006.

24 Sylvia Kleinert, 'An Aboriginal Moomba: Remaking History', Continuum, vol. 13, no. 3, 1999, pp. 345-6.

25 Henry, p. 586.

26 Michael Morrissey, Rogelia PePua, Alex Brown and Ahmed Latif, 'Culture as a Determinant of Aboriginal Health', in Ian Anderson, Fran Baum and Michael Bentley (eds), Beyond Bandaids: Exploring the Underlying Social Determinants of Aboriginal Health, Cooperative Research Centre for Aboriginal Health, Darwin, 2007, p. 245.

27 Jeremy Gaia, personal conversation with author, Cairns, 5 May 2008.

28 Dockery, p. 22.

29 The Laura Dance Festival workshop was held by ASTIAB, as a part of their Celebrations festival strategy, in Cairns, 5-6 May 2008. 
30 See Melbourne Charter for Promoting Mental Health and Preventing Mental and Behavioural Disorders, From 'Margins to Mainstream: 5th World Conference on the Promotion of Mental Health and the Prevention of Mental and Behavioural Disorders', in Melbourne, Australia, September 2008, http://www.vichealth.vic. gov.au/Resource-Centre/Publications and Resources/Mental-health-promotion/ Melbourne-Charter.aspx.

31 Durie in Morrissey, p. 249.

32 Leonore Manderson, 'Social Capital and Inclusion: Locating Wellbeing in Community', in Lenore Manderson (ed.), Rethinking Wellbeing, Curtin University Publishing, Perth, 2005, p. 184.

33 Interviews undertaken at the Dreaming Festival, Woodford, Queensland, 7 June 2008.

34 Jean-Francois Lyotard, The Post-modern Explained to Children: Correspondence 1982-1985, trans. Don Berry, eds Julian Pefanis and Morgan Thomas, Power Publications, Sydney, 1992, p. 42.

35 Michael Dodson, 'The End in the Beginning: Re(de)finding Aboriginality', in Michele Grossman (ed), Blacklines: Contemporary Critical Writing by Indigenous Australians, Melbourne University Press, Melbourne, 2003, p. 33.

36 The Indigenous-led social justice organisation, People Culture Environment in partnership with Our Generation Media produced the report. It is one of the initial actions of the Culture Is Life campaign, http://www.cultureislife.org. The quotes are from the Chairman of People Culture Environment, Max Harrison, in his foreword to the report, p. 8.

37 See http://www.dpmc.gov.au/accountability/budget/2014-15/IA_budget.cfm. 